\title{
Molecular Mechanism of Formalin-Induced Toxicity and Its Management
}

\author{
Alpana Khatun ${ }^{1}$, Md Masud Rana ${ }^{1}$, Md Rafiqul Islam Khan ${ }^{1}$, Mir Imam Ibne Wahed ${ }^{1}$, \\ Md. Anwar Habib ${ }^{2}$, Md. Nazim Uddin ${ }^{2}$, Zakia Sultana Sathi ${ }^{3}$, A. R. M. Ruhul Amin ${ }^{4}$, \\ Abu Syed Md Anisuzzaman ${ }^{1,4, *}$ \\ ${ }^{1}$ Department of Pharmacy, University of Rajshahi, Rajshahi-6205, Bangladesh \\ ${ }^{2}$ Department of Pharmacology and Therapeutics, Rajshahi Medical College, Rajshahi-6000, Bangladesh \\ ${ }^{3}$ Department of Pharmacy, Daffodil International University, Dhaka 1207, Bangladesh \\ ${ }^{4}$ Department of Hematology \& Medical Oncology, Winship Cancer Institute, Emory University, Atlanta, GA 30322, USA \\ Email address: \\ a_zamanpan@yahoo.com (A. S. M. Anisuzzaman), aanisuz@emory.edu (A. S. M. Anisuzzaman)
}

\section{To cite this article:}

Alpana Khatun, Md Masud Rana, Md Rafiqul Islam Khan, Mir Imam Ibne Wahed, Md. Anwar Habib, Md. Nazim Uddin, Zakia Sultana Sathi, A. R. M. Ruhul Amin, Abu Syed Md Anisuzzaman. Molecular Mechanism of Formalin-Induced Toxicity and Its Management. American Journal of Life Sciences. Vol. 3, No. 2, 2015, pp. 85-92. doi: 10.11648/j.ajls.20150302.15

\begin{abstract}
The use of formalin (40\% formaldehyde) for the preservation of food in an illegal way becoming a serious health issue in developing countries including Bangladesh. We investigated the Formalin (FA)-induced organ toxicity in Swiss albino mice. FA induction caused the significant elevation of the liver enzyme, SGOT and SGPT; the MDA levels in the liver and brain. Among the fractions of methanol extract of L. globosus, ethyl acetate (EA) fraction significantly reduced the elevated biochemical parameters (FA vs FA + EA fraction, $\mu \mathrm{Ka} / \mathrm{L}$ ); SGOT (78.4 \pm 0.3 vs $14.3 \pm 0.9)$, SGPT (100.5 \pm 5.2 vs $14.6 \pm 0.7$ ), MDA in liver $(10.9 \pm 0.2$ vs $5.6 \pm 0.1)$ and MDA in brain $(16.9 \pm 0.2$ vs $6.3 \pm 0.2)$. Morphological analyses also supported the beneficial effect of EA fraction in FA-induced liver toxicity. FA induction caused the phosphorylation of JNK, member of mitogen activated protein kinase (MAPK) in both the liver and brain, which were completely abolished by the treatment of EA fraction of L. globosus. Chemical analyses showed that the EA fraction exhibited antioxidant and free radical scavenging properties. The protective effect of the EA fraction on the FA-induced toxicity by the modulation of oxidative inflammatory pathway by its antioxidant and free radical scavenging activity.
\end{abstract}

Keywords: Loranthus globosus, SGOT and SGPT, Antioxidant and Free Radical Scavenging, JNK Phosphorylation, Formalin

\section{Introduction}

Formaldehyde is one of the common environmental agents found in tobacco smoke, paint, diesel, gasoline exhaust, and medical and industrial products (Flyvholm and Andersen 1993). It has been considered to be potentially carcinogenic that makes it a subject of major environmental concern (Heck, Casanova et al. 1990). In Bangladesh, FA is used as an illegal practice to preserve fish, fruits and vegetables which is dangerously affecting the health of local peoples. FA is an extremely reactive chemical, and reacts with monoamines or amides to form methylene bridges and produces covalently cross-linked complexes with proteins and DNA (Saito, Nishio et al. 2005). In addition to DNA-protein cross-links, it has been reported that FA modulates the cellular glutathione
(GSH)status and generates oxidative free radicals (Teng, Beard et al. 2001, Saito, Nishio et al. 2005). Some studies have linked chronic FA exposure not only to cancer incidence, but also to teratogenicity, and to a variety of neurodegenerative and vascular disorders (Kilburn 1994, Sakanashi, Rogers et al. 1996, Yu, Wright et al. 2003).

When ingested, FA is rapidly metabolized and removed from the liver. The major metabolic enzymes, particularly NAD-dependent aldehyde dehydrogenase and GSHdependent formaldehyde hydrogenase are involved in the metabolism of FA, which has been detected in human liver and red blood cells and in a number of animal tissues, such as respiratory and olfactory epithelium in the rat (Teng, Beard et 
al. 2001, Bakand, Hayes et al. 2005).

Various exogenous agents including FA can induce the generation of reactive oxygen species (ROS)(Riley 1994). An excess generation of ROS in cells is known to damage DNA, lipids and proteins, resulting in a number of untoward pathophysiological effects such as mutagenesis, malignant transformation, cell death etc.(Wiseman and Halliwell 1996, Berlett and Stadtman 1997, Thannickal and Fanburg 2000). At the initial stage, to eliminate deleterious ROS from the body, cells utilize various enzymatic and non-enzymatic antioxidants. However, due to excessive oxidative stress, the body's endogenous antioxidant source become exhausted which necessitates the supply of exogenous antioxidants.

In the present study, we investigated the antioxidant compound(s) in the methanolic extracts and its various fractions of Loranthus globosus and evaluated their protective effects against FA-induced organ injury in mouse model. We have analyzed serum glutamate oxaloacetate transaminase (SGOT) and serum glutamate pyruvate transaminase (SGPT) levels as biomarkers for liver injury, malondialdehyde (MDA) as biomarker for lipoid peroxidation in liver and brain. The signaling mechanisms of FA-induced oxidative damage and the protective effects of $L$. globosus were also investigated.

\section{Materials and Methods}

\subsection{Reagents}

Dexamethasone was gifted from the Chemico pharmaceuticals Ltd., Rajshahi, Bangladesh. $0.9 \% \mathrm{NaCl}$ solution (Beximco Infusion Lab., Dhaka, Bangladesh), SGOT and SGPT (AMP Medizintechnik GmbH; Austria), gallic acid standard, trichloro acetic acid, thiobarbituric acid, MDA standard and n-butanol (GE Health care, Buckinghamshire, UK) $\alpha, \alpha$-diphenyl- $\beta$-picrylhydrazyl (DPPH), sodium phosphate, ammonium molybdate, ascorbic acid and methanol (Sigma Aldrich, St. Louis, USA), anti-cJun N-terminal kinase (JNK), anti-phospho-JNK and anti- $\beta$ actin (Cell Signaling Technology, Inc., Massachusetts, USA) were obtained from the sources noted. All employed chemicals and solvents were of analytical grade.

\subsection{Plant Materials}

The barks of L. globosus were collected from Pabna, Bangladesh and were taxonomically identified by Dr. Md. Anisuzzaman, Associate Professor, Department of Botany, University of Rajshahi, Bangladesh and the voucher specimen has been preserved there. The cleaned stem barks were dried under sunshine and subsequently in oven at $50^{\circ} \mathrm{C}$ temperatures for complete dryness.

\subsection{Extraction and Fractionation of Plant Materials}

The dried and pulverized plant material was cold extracted by methanol as described previously (Khan, Islam et al. 2010) and the methanolic extract (ME) was successively partitioned with petroleum ether (PE), chloroform (CF) and ethyl acetate
(EA) using modified Kupchan partitioning method (BC, R et al. 1993). The resultant fractions were then evaporated by roto-dryer at low temperature $\left(40-50^{\circ} \mathrm{C}\right)$ to dryness. The fractions were preserved at $-20^{\circ} \mathrm{C}$ until use. Dimethyl sulfoxide was used as a solvent for the preparation of dose of various fractions.

\subsection{Chemical Analysis of the Methanol Extract and Its Fractions}

\subsubsection{Determination of Total Phenolic (TP) Content}

The total phenolic (TP) content of the crude methanolic extract (ME) of L. globosus and its various fractions (PE, CF, EA) were determined by Folin-Ciocalteu Reagent (FCR) according to the method of Kumar et al. (Kumar, Ganesan et al. 2007) with slight modification. Briefly, the solution of each extract $(0.5 \mathrm{ml}, 1 \mathrm{mg} / \mathrm{ml})$ was diluted to $10 \mathrm{ml}$ with distilled water in a volumetric flask. FCR $(1 \mathrm{ml})$ was added and mixed thoroughly, and then sodium carbonate solution ( 3 $\mathrm{ml}, 2 \%$ ) was added. After $2 \mathrm{~h}$ incubation at room temperature, absorbance was measured at $760 \mathrm{~nm}$. The total phenolic content was determined by comparison with the standard calibration curve of gallic acid, and results are presented as $\mathrm{mg}$ of gallic acid equivalents (mg of GAE) per gram dry weight of extracts. All tests were conducted in triplicate.

\subsubsection{Determination of Total Flavonoid (TF) Content}

The total flavonoid content of each extract was estimated by Zhishen et al.(Zhishen, Mengcheng et al. 1999). Briefly, $0.5 \mathrm{ml}(1 \mathrm{mg} / \mathrm{ml})$ of each sample was mixed with $2 \mathrm{ml}$ of distilled water and subsequently with $0.15 \mathrm{ml}$ of $\mathrm{NaNO}_{2}$ solution (15\%). After incubation for $6 \mathrm{~min}, 0.15 \mathrm{ml}$ of $\mathrm{AlCl}_{3}$ solution $(10 \%)$ was added and allowed to stand for another 6 min. Then $2 \mathrm{ml}$ of $\mathrm{NaOH}$ solution (4\%) was added to the mixture and adjusted the final volume to $5 \mathrm{ml}$ by distilled water. The mixture was then mixed thoroughly and allowed to stand for another $15 \mathrm{~min}$. The absorbance of the final solution was determined at $510 \mathrm{~nm}$. The total flavonoid content was determined by comparison with the standard calibration curve of gallic acid, and results are presented as $\mathrm{mg}$ of gallic acid equivalents (mg of GAE) per gram dry weight of extracts.

\subsection{In Vitro Antioxidant Assay}

\subsubsection{DPPH Radical Scavenging Assay}

The plant extracts were tested for the scavenging effect on DPPH radical according to the method of Pan et al. (Pan, Wang et al. 2008). Accordingly, $0.2 \mathrm{ml}$ of extract solution in ethanol $(95 \%)$ at different concentrations $(1,2,4,8,16,32$ and $64 \mu \mathrm{g} / \mathrm{ml}$, respectively) was added to $8 \mathrm{ml}$ of $0.004 \%$ $(\mathrm{w} / \mathrm{v})$ stock solution of DPPH in ethanol (95\%). The scavenging activity on the DPPH radical was determined by measuring the absorbance at $517 \mathrm{~nm}$ until the reaction reached the steady state, using a UV-visible spectrophotometer (Shimadzu, Tokyo, Japan). Ascorbic acid was used as a positive control. The DPPH radical scavenging activity ( $\mathrm{S} \%$ ) was calculated using the following formula: 


$$
\mathrm{S} \%=\left[\left(A_{\text {control }}-A_{\text {sample }}\right) / \mathrm{A}_{\text {control }}\right] \times 100
$$

\subsubsection{Total Antioxidant Activity Assay}

The total antioxidant activity of the methanolic extract and its various fractions of $L$. globosus were assessed by phosphomolybdenum method as described previously (Prieto, Pineda et al. 1999). Briefly, $0.5 \mathrm{ml}$ sample solution of each fraction was mixed with $3 \mathrm{ml}$ of phosphomolybdenum solution comprising: $0.6 \mathrm{M}$ sulphuric acid, $28 \mathrm{mM}$ sodium phosphate and $4 \mathrm{mM}$ ammonium molybdate. The mixture was then incubated at $95^{\circ} \mathrm{C}$ for 90 min followed by cooling at room temperature. The absorbance of the solution was measured at $695 \mathrm{~nm}$ against blank. Ascorbic acid was used as a positive control.

\subsection{Induction of FA-Induced Organ Injury in Mouse Model}

Male Swiss albino mice weighing about 25 - 30gm were used for the FA-induced animal model study. To measure FAinduced toxicity, we adopted several routes of administration as follows:

i. Oral administration of 4\% FA mixing with fruits daily for one month.

ii. Oral administration of 4\% FA with drinking water daily for one month.

iii. Intraperitoneal (IP) administration of $4 \% \mathrm{FA}(0.1 \mathrm{ml} /$ day $)$ for seven days.

iv. Subcutaneous (SC) administration of $4 \%$ FA $(0.1 \mathrm{ml} /$ day $)$ through hind paws for seven days.

\subsection{Analysis of Various Biochemical Parameters}

After completion of treatment (FA, drug, plant extract), mice were sacrificed and approximately 2-3 $\mathrm{ml}$ of blood was collected directly from heart by syringes, centrifuged at 4000rpm for 30minutes to collect supernatants. Serum GOT and GPT levels were measured by UV-visible spectrophotometric method using commercial wet reagent diagnostic kits (AMP Medizintechnik GmbH; Austria) according to the manufacturer's protocol. Briefly, the amount of oxaloacetate and pyruvate formed by each of the two assays were measured by means of the 2, 4 dinitrophenylhydrazone of pyruvic acid, the color of which was read at $520 \mathrm{~nm}$ by spectrophotometer. The intensity of color was proportional to the amount of enzyme in each sample.

\subsection{Analysis of Malondialdehyde (MDA)}

The MDA levels on the tissues were determined by the method of Draper and Hadley based on the reaction of MDA with thiobarbituric acid (TBA) at $95^{\circ} \mathrm{C}$ (Draper and Hadley 1990). The brain and liver tissues were homogenized separately on ice in MDA lysis buffer and centrifuged at $13,000 \times \mathrm{g}$ for $10 \mathrm{~min}$ to collect the supernatant. In the TBA test reaction, MDA and TBA react to form a pink pigment with absorption maximum at $532 \mathrm{~nm}$. The reaction was performed at $\mathrm{pH} 2-3$ at $95^{\circ} \mathrm{C}$ for $15 \mathrm{~min}$. The supernatant was mixed with 2.5 volumes of $10 \%(\mathrm{w} / \mathrm{v})$ trichloroacetic acid to precipitate the protein. The precipitate was pelleted by centrifugation and supernatant was reacted with $0.67 \%$ TBA in a boiling water bath for $15 \mathrm{~min}$. After cooling, the absorbance was read at $532 \mathrm{~nm}$. Arbitrary values obtained were compared with a series of standard solutions $(1,1,3,3$ tetramethoxypropane). Results are expressed as nmol per milligram of tissue.

\subsection{Immunoblotting}

The liver and brain samples from the respective animal groups were dissected and placed immediately into ice-cold phosphate-buffered saline (PBS). The collected tissues were homogenized by sonication with an ultrasonic homogenizer (VP-050, Taitec Corp., Koshigaya, Japan) followed by lysis with RIPA buffer (50 mM Tris- $\mathrm{HCl}, 1 \% \mathrm{NP}-40,0.25 \% \mathrm{Na}-$ deoxycholate, and $150 \mathrm{mM} \mathrm{NaCl}, 1 \mathrm{mM} \mathrm{Na} \mathrm{VO}_{4}$ and $\mathrm{NaF}$ ) containing protease inhibitors $(1 \mu \mathrm{g} / \mathrm{ml}$ each of EDTA and phenylmethylsulfonyl fluoride). Cell lysates were centrifuged at $12,000 \times \mathrm{g}$ for $15 \mathrm{~min}$ at $4^{\circ} \mathrm{C}$. The supernatant was collected and boiled with SDS sample buffer (12 mM Tris- $\mathrm{HCl}, 10 \%$ glycerol, $10 \%$ sodium dodecyl sulfate and 1\% 2mercaptoethanol and $0.1 \%$ bromophenol blue, $\mathrm{pH} 6.8$ ) for 5 min at $100^{\circ} \mathrm{C}$. Proteins were separated by SDS-PAGE and transferred to polyvinylidene fluoride (PVDF) membranes. Membranes were probed with appropriate concentrations of primary antibody. The immunoreactive proteins were detected by horseradish-peroxidase-labeled secondary antibody with Amersham ECL advance Western blotting Detection Kit (GE healthcare).

\subsection{Histopathological Study}

After seven days of observation, the animals were killed by cervical dislocation. The liver was carefully excised, rinsed in cold sucrose solution, and blotted in dry filter paper. The specimen was fixed with $10 \%$ buffered-formalin and dehydrated in ascending order of ethanol and embedded in paraffin. The blocks were sectioned with the help of rotation microtome at 6-micron thickness. The sections were subjected to Hematoxylin and Eosin staining procedures and the histological examination was done with the aid of the high power microscope. The histological outline of each photomicrograph was conducted through a stereological grid in order to access the population of the cells in each organ. The permanent photomicrographs of each slide were recorded with a Kodak Digital Camera for subsequent histological analysis.

\subsection{Statistical Analysis}

Data were expressed as mean \pm standard error of mean (SEM). Statistical comparisons were performed by one-way analysis of variance (ANOVA), followed by Scheffe's posthoc test or students paired or unpaired t-test where appropriate. Results were considered to be significant when $p$ values were less than $0.05(p<0.05)$. Statistical calculations and the graphs were prepared using Graph Pad Prism version 
5.00 for Windows (Graph Pad Software, San Diego, CA, USA, www.graphpad.com).

\section{Results}

\subsection{Chemical Analysis of Total Phenol and Flavonoid Contents of the Crude Methanol Extract (ME) and Its Fractions of L. globosus}

Table 1. Determination of total phenol and flavonoid contents in the crude methanol (ME) extract and its various fractions of L. globosus.

\begin{tabular}{lll}
\hline \multirow{2}{*}{ Sample } & Total phenol & Total flavonoid \\
\cline { 2 - 3 } & GAE/gm of dried extracts & GAE/gm of dried extracts \\
\hline ME extracts & $73.07 \pm 0.08$ & $198.43 \pm 5.19$ \\
PE fractions & $14.03 \pm 0.03$ & $102.50 \pm 11.3$ \\
EA fractions & $114.84 \pm 0.20$ & $276.90 \pm 16.34$ \\
CF fractions & $31.84 \pm 0.04$ & $53.21 \pm 6.09$ \\
\hline
\end{tabular}

The phenolic and flavonoid compounds are considered as potential antioxidants and free radical scavengers. Here, we investigated the contents of total phenol (TP) and total

\section{A}

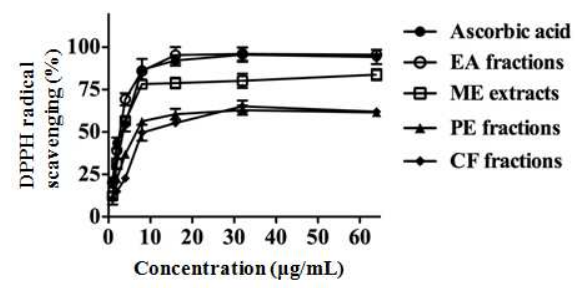

flavonoid (TF) compounds in the various fractions (PE, CF and EA) of methanolic extracts of L. globosus. The results are shown in Table 1. The highest amount of TP and TF contents were found in EA fractions (114.84 \pm 0.20 and $276.90 \pm 16.34 \mathrm{GAE}$ per gram, respectively).

\subsection{In Vitro Antioxidant Activity Analysis of the Crude Methanol Extract (ME) and Its Fractions of $L$. globosus}

The Fig. 1A shows that there was significant scavenging of DPPH free radicals on various fractions of L. globosus. Maximum scavenging of $95.6 \pm 2.5 \%$ was observed by EA fractions in a similar extent to that of standard ascorbic acid $(94.3 \pm 4.2 \%)$, followed by CF $(62.0 \pm 1.2 \%)$ and PEF $(61.5$ $\pm 2.4 \%$ ), respectively.

Similarly, the Fig. 1B shows that the EA fractions have the highest total antioxidant activity. The order of total antioxidant activity in various fractions of $L$. globosus were $\mathrm{EA}>\mathrm{PE}>\mathrm{CF}$. The results are concordant with the contents of total phenolic and total flavanoid in various fractions.

B

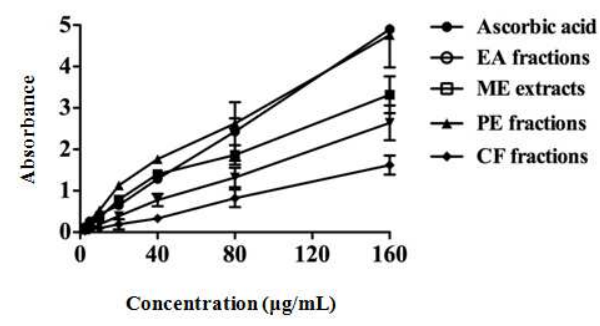

Fig. 1. In vitro antioxidant activity of the methanol extract and fractions of L. globosus: (A) DPPH radical scavenging activity of crude methanol extracts (ME) and its various fraction of L. globosus. (B) Total antioxidant activity of the crude methanol extract (ME) and its various fractions of L. globosus. Ascorbic acid was used as standard scavenger of the oxidant as well as standard antioxidant agent.

\subsection{Time Course of FA-Induced Liver Injury}

A

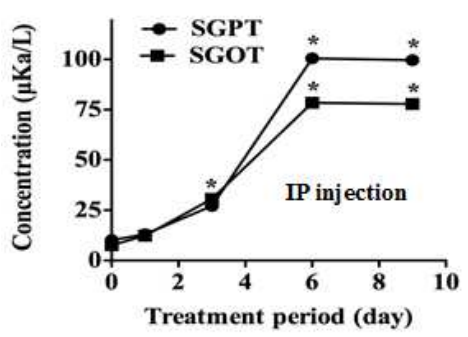

C

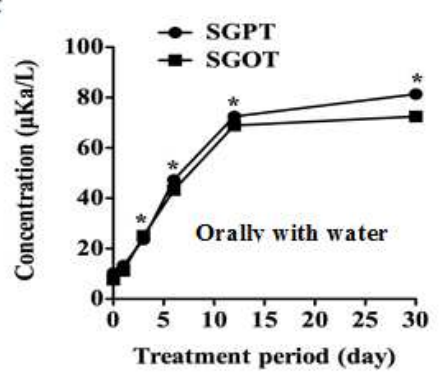

B

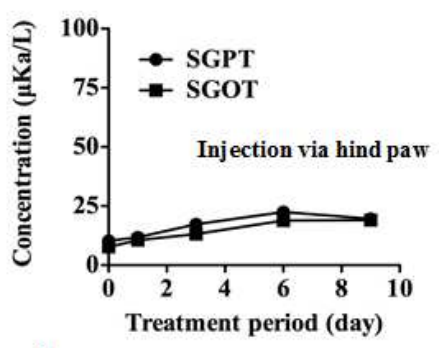

D

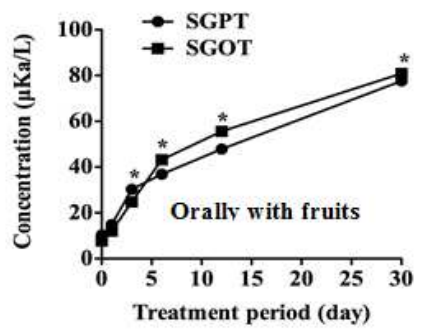

Fig. 2. Time course of FA-induced elevation of liver enzymes (SGOT and SGPT) in various routes of administration. FA was supplied by (A) intraperitoneal injection; (B) hind paw injection; (C) oral route with drinking water and (D) oral route with fruits. ${ }^{\star}$ indicates significantly different ( $\left.p<0.05\right)$ from time control after treatment with FA. 
In order to estimate the FA-induced liver injury, we measured SGPT and SGOT levels at various time periods upon FA treatment for different routes of administration. The intraparetoneal (IP) route of administration shows approximately 10-fold maximum increase of both the liver enzymes (Fig. 2A) on $6^{\text {th }}$ day of administration as compared to control. In the case of oral routes, similar increase of liver enzymes were achieved at longer duration (15-30 days) as shown in Fig. 2C and 2D. Elevated level of both the enzymes was least when injected in the hind paw (Fig. 2B). Because of the difficulty in dose adjustment along with administration in oral route and less sensitivity to hind paw, we chose IP administration for 7-day FA treatment period in our experimental model.

\subsection{Ethyl Acetate (EA) Fraction of L. globosus Reduces the FA-Induced Elevated SGOT and SGPT Levels in a Dose-Dependent Manner}

Since the EA fraction of L. globosus possesses the maximum amount of antioxidant compounds (TP and TF), we investigated the effect of this fraction on the FA-induced elevated SGOT and SGPT levels. Single IP injection of EA fraction reduced the FA-induced elevation of SGOT and SGPT levels in a dose dependent manner (Fig. 3). EA fraction at $12-\mathrm{mg} / \mathrm{kg}$-body weight reduced the elevated SGOT and SGPT levels completely. 12-mg/kg-body weight of EA fraction of L. globosus were used for further experiments unless mentioned.

\section{Serum}

$\mathbf{A}$

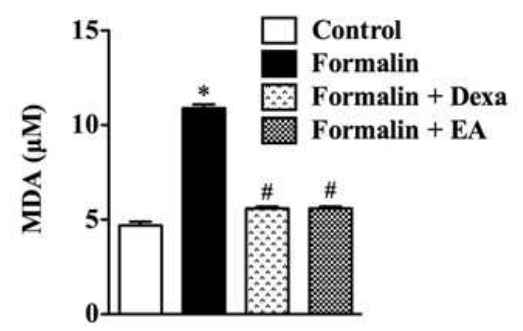

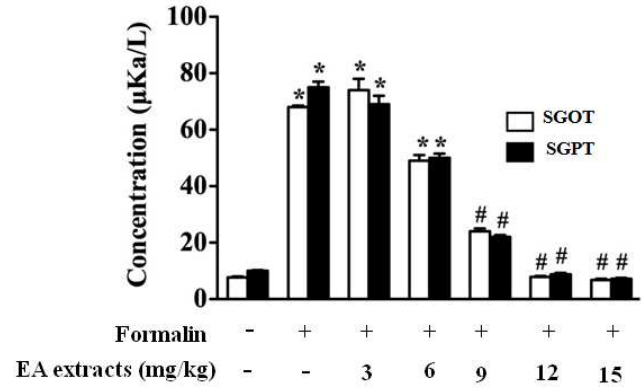

Fig. 3. Dose dependent effect of ethyl acetate froction of L. globosus on formalin induced elevated SGOT and SGPT. Reduction of FA-induced elevated SGOT and SGPT by EA fraction of L. globosus in a dose-dependent manner.* indicates significant $(p<0.05)$ elevation of SGOT and SGPT after FA induction as compared to normal control. ${ }^{*}$ indicates significant $(p<0.05)$ reduction of SGOT and SGPT upon treatment of EA fraction as compared to FA-induced control.

\subsection{Ethyl Acetate (EA) Fraction of L. globosus Suppress the FA-Induced Lipid Peroxidation}

Malondialdehyde (MDA) is one of the most important biomarker of lipid peroxidation, which is generated due to the excessive load of free radicals. In the present study, we found that IP administration of FA caused the elevation of serum and brain MDA levels which were suppressed significantly by the co-administration of single IP injection of EA fraction of L. globosus in a similar extent to that of standard anti-inflammatory drug, dexamethasone. The results are shown in Fig. 4A and 4B.

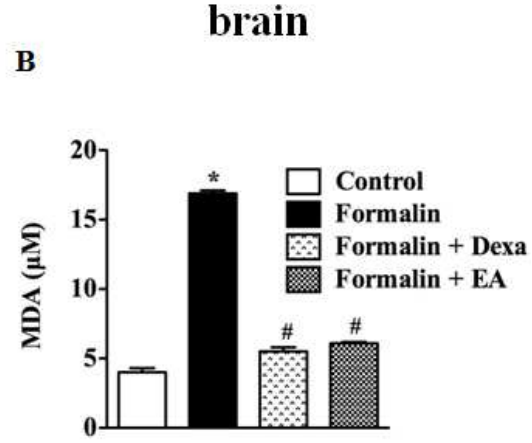

Fig. 4. Effects of EA fraction of L. globosus on FA-induced elevated MDA level. (A) FA-induced elevated liver MDA level was significantly reduced by the EA fraction of L. globosus in a similar extent to that of anti-inflammatory drug, dexamethasone. (B) FA-induced elevated brain MDA level was significantly reduced by the EA fraction of L. globosus in a similar extent to that of anti-inflammatory compound, dexamethasone (Dexa). * indicates significant ( $<<0.05)$ elevation of MDA level after FA induction as compared to normal control. ${ }^{*}$ indicates significant $(p<0.05)$ reduction of MDA level after treatment of EA fraction as compared to FA-induced control. Concentration of dexamethasone and EA fraction of L. globosus were 2 and 12 mg/kg body weight, respectively.Values are mean $\pm \operatorname{SEM}(n=4)$.

\subsection{Histopathology of Liver Tissues after FA-Induced Damage}

Liver tissues were collected from the control and treatment group of mice were fixed and stained with Hematoxylin and Eosin as described in methods. The specimens were then visualized under microscope with $40 \times$ magnifications. As shown in Fig. 5B, there was swelling of liver tissues with marked fatty degeneration with FA treatment. Areas of focal necrosis were also observed in the liver of the FA-induced mice as compared to the control (Fig.5A). The histopathological degeneration was repaired considerably by the supplementation of EA fraction of L. globosus as shown in Fig. 5D. 


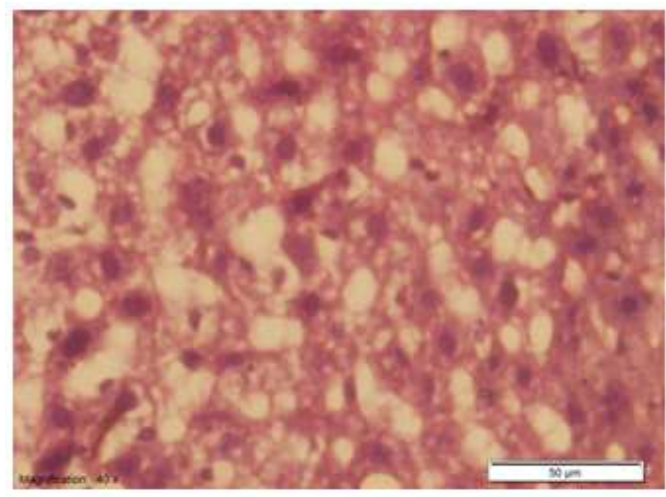

A. Control

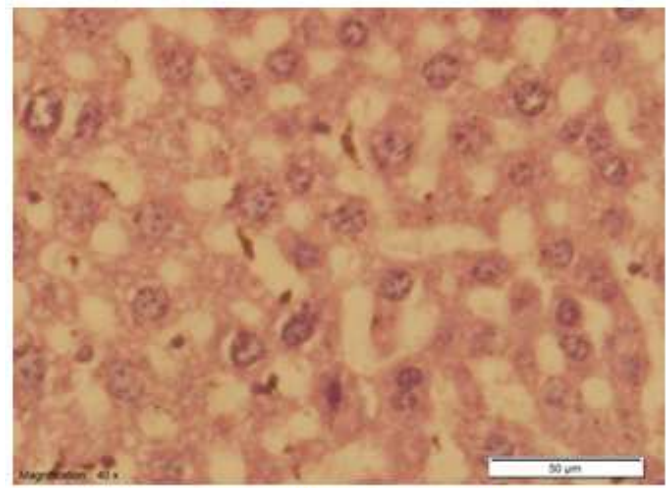

C. Formalin + Dexamethasone

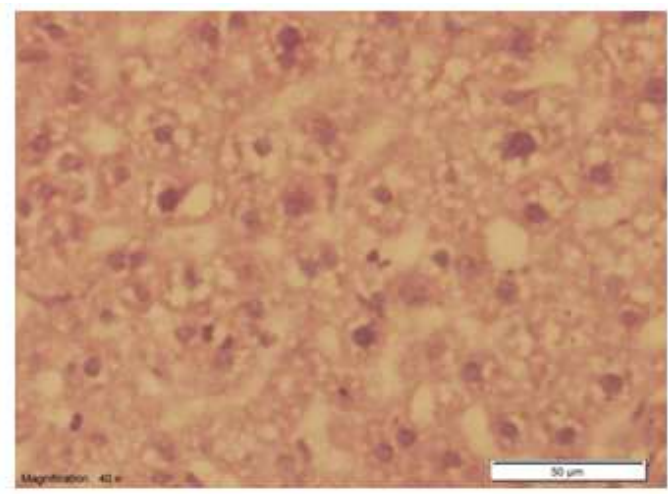

B. Formalin

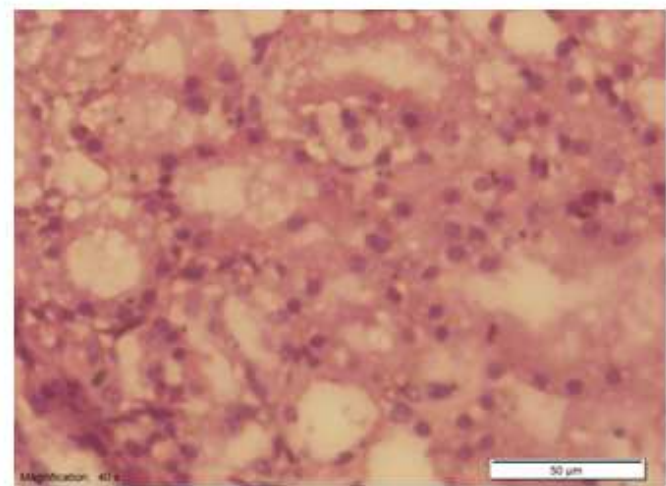

D. Formalin + EA of L. globosus

Fig. 5. Histopathological studies of FA-induced liver damage with or without the treatment of EA fraction of L. globosus and Dexamethasone. The representative photographs shown are (A) normal control (B) FA-induced control (C) FA-induced mice with the supplementation of anti-inflammatory compound, dexamethasone and (D) FA-induced mice with the supplementation of EA fraction of L. globosus. Scale bars, 50 um.

\subsection{Ethyl Acetate (EA) Fraction of L. globosus Suppress the FA-Induced Phosphorylation of c-Jun N-Terminal Kinase (JNK)}

The c-Jun N-terminal kinase (JNK) pathway is important in modulating cellular responses to inflammation and oxidative stress. Since FA is an inflammatory mediator, we estimated the phosphorylation levels of JNK in serum and

\section{Liver}

$\mathbf{A}$

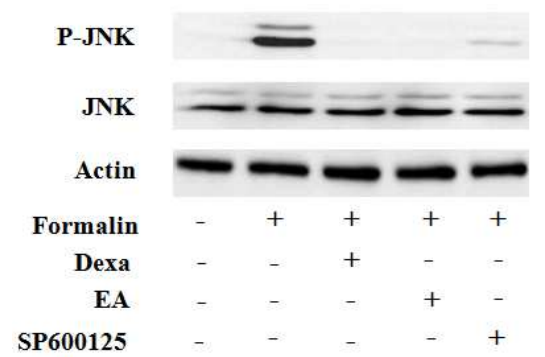

brain after 7 day of FA treatment. There was approximately 10-fold significant increase of serum (Fig. 6A) and brain (Fig. 6B) phospho-JNK levels above the baseline. Coadministration of EA fraction of L. globosus completely abolished the FA-induced phospho-JNK levels both in liver and brain, suggesting the potential anti-inflammatory and anti-oxidant effects of the fraction.

\section{Brain}

B

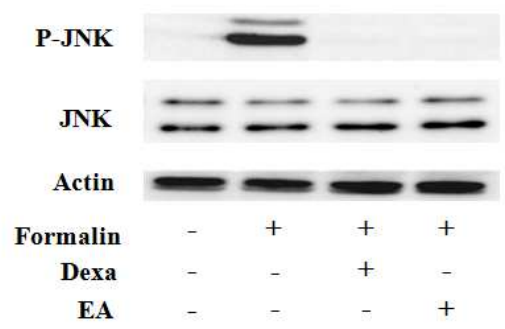

Fig. 6. FA-induced activation of JNK in mouse liver and brain. (A) FA-induced Phosphorylation of JNK in mouse liver tissue. (B) FA-induced Phosphorylation of JNK in mouse brain tissue. Samples were collected from liver and brain tissues, 7 days after FA induction and were lysed, separated in SDS-PAGE, blotted and probed with anti-phospho-JNK, anti-JNK and anti- $\beta$ actin. $(n=3)$. 


\section{Discussion}

The serum enzyme levels are direct measure of hepatic injury and they show the status of the liver. The elevation of enzymes induced by FA causes hepatotoxicity which may be due to its metabolite, a free radical that binds to lipoprotein and leads to peroxidation of lipids of endoplasmic reticulum. The disturbance in the transport function of the hepatocytes as a result of hepatic injury causes the leakage of enzymes from cells due to altered permeability of membrane (Zimmerman and Seeff 1970). The increased serum GOT and GPT level is evidence that these enzymes play an important role in the development of acute and chronic inflammation (Anderson, Bocklehurst et al. 1971).

In this study, we found that EA fractions of L. globosus significantly suppressed the FA-induced elevated SGOT and SGPT levels (Fig. 3). Most of the anti-inflammatory drugs exert their beneficial effect by inhibiting either release of these enzymes or by stabilizing lysosomal membrane which is one of the major events responsible for the inflammatory process (Nair, Ravishankar et al. 1988). Thus it can be assumed that EA fractions of $L$. globosus might be acting by either inhibiting the enzymes or stabilizing the membrane.

The elevated level of MDA, which may be due to the free radicals, is responsible for damaging cell membranes and further intensifies inflammatory damage (Telang, Chatterjee et al. 1990). The inflammatory tissue damages could be due to the liberation of reactive oxygen species from phagocytes that invades the inflammatory sites (Conner and Grisham 1996).

In the present study, we found that the concentration of MDA in brain and liver tissues was found to be higher in FAinduced mice, which were reduced significantly by treatment with the EA fractions of L. globosus (Fig. 4). The increased MDA levels in the serum and brain also comprise with the previous report by Teng et al. (Teng, Beard et al. 2001).

We demonstrated that EA fractions of methanolic extracts of L. globosus exhibited potential antioxidant and free radical scavenging capacity (Fig. 1) due to the presence of flavonoids and phenolic compounds (Table 1). Hence, we assumed that the protective effect of EA fraction could be the result of direct free radical scavenging properties (Gurel, Coskun et al. 2005) or by reacting with membrane phospholipid bilayers to break the chain reaction initiated by ROS (Verma and Nair 2001). Histological analyses also supported the protective effects of EA fractions of $L$. globosus (Fig. 5).

Finally, we discovered the molecular mechanism of the ameliorative effects of EA fraction of L. globosus against organ toxicity by investigating the intracellular signaling events. Our results clearly shows that FA induction caused the activation of oxidative stress responsive JNK pathway, a member of the mitogen-activated protein kinase (MAPK) family in the brain and liver, which were completely suppressed by the supplementation of EA fractions of $L$. globosus. All isoforms of JNK are constitutively expressed in the liver and brain, which plays a key role in cell death and hepatotoxicity. JNK activation has been well recognized in both rodent and human liver diseases (Malhi, Bronk et al. 2006, Puri, Mirshahi et al. 2008, Wang, Ausman et al. 2008).

\section{Conclusion}

FA induction caused the elevation of liver biomarkers; SGOT and SGPT and lipid peroxidation biomarker, MDA in liver and brain tissues, which were suppressed towards normal levels by the supplementation of the EA fractions of L. globosus presumably via the suppression of oxidative stress responsive JNK pathway by its antioxidant and free radical scavenging activity. Although more detailed mechanisms need to be further investigated, the present work provides a potential strategy for treating liver and brain damage. Therefore, the modulation of JNK pathway could be a good target in the treatment of liver and brain toxicity.

\section{Acknowledgements}

This work was supported in part by the Ministry of Education, People's Republic of Bangladesh.

\section{Abbreviations}

FA, formalin; SGOT, serum glutamate oxalate transaminase; SGPT, serum glutamate pyruvate transaminase; MDA, malondialdehyde; EA, ethyl acetate; ME, methanol extract; PE, petroleum ether; CF, chloroform; MAPK, mitogen activated protein kinase; DPPH, $\alpha, \alpha$-diphenyl- $\beta$ picrylhydrazyl.

\section{References}

[1] Anderson, A. J., et al. (1971). "Evidence for the role of lysosomes in the formation of prostaglandins during carrageenan induced inflammation in rat." Pharmacol Res Comm 3: 13-17.

[2] Bakand, S., et al. (2005). " In vitro cytotoxicity testing of airborne formaldehyde collected in serum-free culture media." Toxicol Ind Health 21(7-8): 147-154.

[3] BC, V. W., et al. (1993) "Ulosantoin, a potent insecticide from the sponge Ulosa ruetzleri." J Org Chem 58: 335-337

[4] Berlett, B. S. and E. R. Stadtman (1997). "Protein oxidation in aging, disease, and oxidative stress." J Biol Chem 272(33): 20313-20316.

[5] Conner, E. M. and M. B. Grisham (1996). "Inflammation, free radicals, and antioxidants." Nutrition 12(4): 274-277.

[6] Draper, H. and M. Hadley (1990). "Malondialdehyde determination as index of lipid peroxidation." Methods Enzymol 186: 421-431. 
[7] Flyvholm, M. A. and P. Andersen (1993). " Identification of formaldehyde releasers and occurrence of formaldehyde and formaldehyde releasers in registered chemical products." Am J Ind Med 24(5): 533-552.

[8] Gurel, A., et al. (2005). "Vitamin E against oxidative damage caused by formaldehyde in frontal cortex and hippocampus: biochemical and histological studies." J Chem Neuroanat 29: 173-178.

[9] Heck, H. D., et al. (1990). "Formaldehyde toxicity-new understanding." Crit Rev Toxicol 20(6): 397-426.

[10] Khan, M. R. I., et al. (2010). "Antidiabetic Effects of the Different Fractions of Ethanolic Extracts of Ocimum sanctum in Normal and Alloxan Induced Diabetic Rats." J Sci Res 2(1): 158-168.

[11] Kilburn, K. H. (1994). "Neurobehavioral impairment and seizures from formaldehyde." Arch Environ Health 49(1): 3744.

[12] Kumar, K. S., et al. (2007). "Antioxidant potential of solvent extracts of Kappaphycus alvarezii (Doty) Doty - An edible seaweed." Food Chemistry 107: 289-295.

[13] Malhi, H., et al. (2006). "Free fatty acids induce JNKdependent hepatocyte lipoapoptosis." J Biol Chem. 281: 12093-12101.

[14] Nair, R. B., et al. (1988). "Anti inflammatory effect of Strbilanthus heyneanusLeaves-A biochemical study." J Res Ay Sid 9(1-2): 46.

[15] Pan, Y., et al. (2008). "Antioxidant activity of microwaveassisted extract of longan (Dimocarpus Longan Lour.) peel." Food Chemistry 106(3): 1264-1270.

[16] Prieto, P., et al. (1999). "Spectrophotometric quantitation of antioxidant capacity through the formation of a Phosphomolybdenum Complex: Specific application to the determination of vitamin E." Analytical Biochemistry 269: 337-341.

[17] Puri, P., et al. (2008). "Activation and Dysregulation of the Unfolded Protein Response in nonalcoholic fatty liver disease." Gastroenterology 134: 568-576.

[18] Riley, P. A. (1994). "Free radicals in biology: oxidative stress and the effects of ionizing radiation." Int J Radiat Biol 65(1): 27-33.
[19] Saito, Y., et al. (2005). " Cytotoxic effect of formaldehyde with free radicals via increment of cellular reactive oxygen species." Toxicology 210(2-3): 235-245.

[20] Sakanashi, T. M., et al. (1996). "Influence of maternal folate status on the developmental toxicity of methanol in the CD-1 mouse." Teratology 54(4): 198-206.

[21] Telang, R. S., et al. (1990). "Study on analgesic and antiinflammatory avtivities of Vitex negunda Linn." Gen Pharmacol 31(5): 363-366.

[22] Teng, S., et al. (2001). "The formaldehyde metabolic detoxification enzyme systems and molecular cytotoxic mechanism in isolated rat hepatocytes." Chem Biol Interact 130-132(1-3): 285-296.

[23] Teng, S., et al. (2001). "The formaldehyde metabolic detoxification enzyme systems and molecular cytotoxic mechanism in isolated rat hepatocytes." Chem Biol Interact 130-132(1-3): 285-296.

[24] Thannickal, V. J. and B. L. Fanburg (2000). "Reactive oxygen species in cell signaling." Am J Physiol Lung Cell Mol Physiol 279(6): 1005-1008.

[25] Verma, R. J. and A. Nair (2001). "Amerliorative effect of Vitamin $\mathrm{E}$ on aflatoxin-induced lipid peroxidation in the testis of mice." Asian J Androl 3: 217-221.

[26] Wang, Y., et al. (2008). "Increased apoptosis in high-fat dietinduced nonalcoholic steatohepatitis in rats is associated with c-Jun NH2-terminal kinase activation and elevated proapoptotic Bax." J Nutr 138: 1866-1871.

[27] Wiseman, H. and B. Halliwell (1996). " Damage to DNA by reactive oxygen and nitrogen species: role in inflammatory disease and progression to cancer." Biochem J 313: 17-29.

[28] Yu, P. H., et al. (2003). "Physiological and pathological implications of semicarbazide-sensitive amine oxidase." Biochim Biophys Acta 1647(1-2): 193-199.

[29] Zhishen, J., et al. (1999). "The determination of flavonoid contents in mulberry and their scavenging effects on superoxide radicals." Food Chemisty 64(4): 555-559.

[30] Zimmerman, H. J. and L. B. Seeff (1970). "Enzymes in hepatic disease." Diagnostic Enzymology. 1, Lea and Febiger, Philadelphia, USA. 